\title{
Outlier admissions of medical patients: prognostic implications of outlying patients. The experience of the Hospital of Mestre
}

\author{
Francesco Serafini, ${ }^{1}$ Giuseppe Fantin, ${ }^{1}$ Roberto Brugiolo, ${ }^{2}$ Onofrio Lamanna, ${ }^{3}$ Anna Aprile, ${ }^{4}$ Fabio Presotto ${ }^{1}$ \\ ${ }^{1}$ Unit of Internal Medicine; and ${ }^{2}$ Unit of Geriatics, Department of Medicine, Angel Hospital of Mestre (VE); ${ }^{3} \mathrm{Health}$ Care \\ Hospital Direction, Angel Hospital of Mestre (VE); ${ }^{4}$ Legal Medicine Section, Department of Molecular Medicine, University \\ of Padova, Italy
}

\begin{abstract}
The admission of a patient in wards other than the appropriate ones, known as the patient outlying phenomenon, involves both Medicine and Geriatric Units of many Hospitals. The aims were to learn more about the prognosis of the outlying patients, we investigated 3828 consecutive patients hospitalized in Medicine and Geriatrics of our hub Hospital during the year 2012. We compared patients' mean hospital length of stay, survival, and early readmission according to their outlying status. The mean hospital length of stay did not significantly differ between the two groups, either for Medicine (9.8 days for outliers and 10.0 for in-ward) or Geriatrics (13.0 days for both). However, after adjustment for age and sex, the risk of death was about twice as high for outlier patients admitted into surgical compared to medical areas (hazard ratio 1.8, 1.2-2.5 95\% confidence interval). Readmission within 90 days from the first discharge was more frequent for patients admitted as outliers $(26.1 \% v s$ $14.2 \%, \mathrm{P}<0.0001)$. We highlight some critical aspects of an overcrowded hospital, as the shortage of beds in Medicine and Geriatrics and the potential increased clinical risk denoted by deaths or early readmission for medical outlier patients when assigned to inappropriate wards. There is the need to reorganize beds allocation involving community services, improve in-hospital bed management, an extent diagnostic procedures for outlier patients admitted in nonmedical wards.
\end{abstract}

\section{Dear Editor,}

Over the last years Internal Medicine wards in Italy have experienced an increased number of admis-

Correspondence: Francesco Serafini, Unit of Internal Medicine, Angel Hospital, via Paccagnella 11, 30174 Mestre (VE), Italy.

Tel.: +39.0419657414/7415 - Fax: +39.0419657353.

E-mail: francesco.serafini@ulss12.ve.it

Key words: Overcrowding hospital wards; outlying patients; prognostic indicators; short stay area.

Acknowledgments: the authors thank Maurizio Nordio for statistical analysis, and Giulia Cardinali for data collection and processing.

Conflict of interest: the authors have no conflict of interest.

Received for publication: 6 July 2014.

Revision received: 4 August 2014.

Accepted for publication: 26 August 2014.

This work is licensed under a Creative Commons Attribution NonCommercial 3.0 License (CC BY-NC 3.0).

(C) Copyright F. Serafini et al., 2015

Licensee PAGEPress, Italy

Italian Journal of Medicine 2015; 9:299-302

doi:10.4081/itjm.2015.528 sions and medical wards overcrowding is a common scenario..$^{1-3}$ Overcrowding may affect patients' clinical outcome and satisfaction. Either epidemiological and health care organization factors are implicated. Interaction between aging, chronic illness, comorbidities, and socio-economic weakness originated a phenotype of unhealthy subjects, known as frail patients, who are recurrent hospital users and regarded as bed-blockers for their difficult discharge. ${ }^{4,5}$ It has long been an expedient to admit patients waiting for beds in wards different from medical or geriatric units, but this results in an anomaly in health care organization and may have unfavorable prognostic implications. We questioned if outlying status influenced patients' outcomes, like death and readmission, reporting our experience.

The city of Mestre has one public and two private hospitals without Emergency Department (ED). The population is of 250,000 inhabitants, $62.2 \%$ aging 15 64 years and $25.5 \%$ more than 64 years. At the time of this study, our Hospital supplied 465 beds for adults, 239 for medical ( 84 internal medicine, 35 geriatrics, and the remaining for specialty branches) and 226 for surgical specialties. The ED links all metropolitan emergencies with a mean daily presentations of 218 patients (about 80,000 annual presentations). In 2012, 2833 patients were admitted in Internal Medicine and 995 in Geriatrics. Outliers, the term used most frequently in the literature, were defined as patients admitted in beds outside of Medicine or Geriatrics. These patients were 
provided with medical assistance of physicians from Medicine or Geriatrics, but not with nursing support that was in charge to the nurse staff of the accepting ward. Total number of admissions, patient gender, age, degree of dependence, mortality, length of stay, outlying location (medical or surgical), diagnosis related group (DRG) at discharge, and readmission within 90 days were examined. A multivariate model analysis was used to estimate the association between these variables and patient outlying status. Patients admitted in Geriatrics were older ( 85.1 vs 73.3 years) and had a higher degree of dependency at discharge (Barthel index 31 vs 57). No differences were found between outlying and non-outlying status for gender, age, and diagnosis at discharge. Multivariate analysis showed that the risk of being hospitalized as outlier was twice as high for patients assigned to Geriatrics than to Medicine [odds ratio (OR) $2.16,95 \%$ confidence interval (CI) 1.71-2.73], and that patients with respiratory diseases were less likely hospitalised as outliers (OR 0.66, CI 0.48-0.91). The percentage of readmissions within 90 days was higher for outlying patients compared to home ward patients, both for Geriatrics ( $29.9 \%$ vs $7.2 \%, \mathrm{P}<0.0001)$ and Medicine Unit (23.7\% vs 16.3\%, $\mathrm{P}=0.01$ ) (Table 1). After adjustment for age and sex, multivariate analysis showed that the risk of death was about twice higher for outlying pa- tients admitted into surgical compared to medical area [hazard ratio (HR) 1.8, CI 1.28-2.53]. The risk of death was greater for patients with cardiovascular (HR 1.52, CI 1.22-1.89) and gastroenterological DRG (HR 1.52, CI 1.18-1.97) (Table 2).

Analysis on hospital admissions in wards different from appropriate ones highlights problems known in the literature. ${ }^{1-3,6}$ Overcrowding and outlying of medical patients have important prognostic and medicolegal implications. Hospital crowding is a reason for reduced efficiency and quality of care, and it has been related to increased rate of adverse events and medical malpractice claims. ${ }^{7}$ According to the Italian law and jurisprudence, patients' personal injuries or death due to governance inadequacy does not dispense with the medical institution's liability.

Hospitals with mean occupancy rates over $90 \%$ have the greatest risk of providing inadequate care for users, ${ }^{8-10}$ and hospital wards cannot run at around $100 \%$ occupancy for long without increasing patients' clinical risks. ${ }^{71}$ Conversely, an occupancy index around $85 \%$ would give an optimal balance between care efficiency and safety. ${ }^{12,13}$ Over the past years our occupancy rate of Medicine and Geriatrics has always been over $100 \%$, being $106 \%$ for Medicine and $108 \%$ for Geriatrics in 2012.

Table 1. Number of discharges of patients in Medicine and Geriatric wards in the year 2012, number of deaths for all causes, and readmissions within 90 days.

\begin{tabular}{lccccc}
\hline & $\begin{array}{c}\text { Number of } \\
\text { discharges } \\
\mathbf{n}\end{array}$ & $\begin{array}{c}\text { Number of } \\
\text { deaths } \\
\mathbf{n}(\mathbf{\%})\end{array}$ & $\begin{array}{c}\text { Total } \\
\text { number } \\
\mathbf{( \% )}\end{array}$ & $\begin{array}{c}\text { Mean net in-hospital } \\
\text { LOS } \\
\text { (days) }\end{array}$ & $\begin{array}{c}\text { Number of re-admissions } \\
\text { within 90 days } \\
(\mathbf{\%})\end{array}$ \\
\hline $\begin{array}{l}\text { Medicine Unit } \\
\text { In-ward patients }\end{array}$ & 2210 & $424(16.1)^{*}$ & $2634(92.9)$ & 10.0 & $360 / 2210(16.3)^{\circ}$ \\
Outlier patients & 177 & $22(11.1)^{*}$ & $199(7.1)^{\#}$ & 9.8 & $42 / 177(23.7)$ \\
Total & 2387 & $446(15.7)$ & 2833 & 10.0 & $402 / 2387(16.8)$ \\
\hline Geriatric Unit & 669 & $186(21.7)^{*}$ & $855(88.9)$ & 13.0 & $48 / 669(7.2)^{\S}$ \\
In-ward patients & 107 & $33(23.6)^{*}$ & $140(11.1)^{\#}$ & 13.0 & $32 / 107(29.9)$ \\
Outlier patients & 776 & $219(22.0)$ & 995 & 13.0 & $80 / 776(10.3)$ \\
Total & & & & \\
\hline
\end{tabular}

LOS, length of stay. ${ }^{*} \mathrm{P}$ not significant (in-ward $v s$ outlier patients for each Unit); ${ }^{\circ} \mathrm{P}=0.01$ compared to outliers (Medicine); ${ }^{*} \mathrm{P}<0.0001$ outliers in Medicine $v s$ Geriatrics; ${ }^{\circledR} \mathrm{P}<0.001$ compared to outliers (Geriatrics).

Table 2. Hazard ratio with confidence intervals at $95 \%$ indicating the association between mortality and the variables of interest.

\begin{tabular}{|c|c|c|c|}
\hline Considered variables & HR & $95 \% \mathrm{CI}$ & P value \\
\hline Medicine ward & 1 & - & - \\
\hline Surgical area of stay & 1.8 & $1.28-2.53$ & $<0.05$ \\
\hline Medical area of stay & 0.73 & $0.45-1.18$ & ns \\
\hline Other DRG & 1 & - & - \\
\hline DRG neurology & 0.97 & $0.72-1.30$ & ns \\
\hline DRG pneumology & 1.2 & $0.97-1.49$ & ns \\
\hline DRG cardiology & 1.52 & $1.22-1.89$ & $<0.05$ \\
\hline DRG gastroenterology & 1.53 & $1.18-1.97$ & $<0.05$ \\
\hline
\end{tabular}

HR, hazard ratio; CI, confidence interval; ns, not significant; DRG, diagnosis related group. 
In our experience, mortality was found to be twice as high for patients admitted as outliers into surgical areas. The worse prognosis of the outlying patients admitted into surgical wards probably depends on the fact that health staff is less familiar with emergency/urgency procedures of medical frail patients. These and other problems are analyzed in Table 3.

The risk of early readmission in hospital was mainly seen in patients discharged from Geriatrics than Medicine, thus underlying the increased clinical frailty of very-old patients. These data are in agreement with the literature and find a possible explanation in still inadequate organization in discharging frail patients. ${ }^{14}$

Demand for health care is potentially unlimited, especially in a free public health care system. Government of acute hospitals congestion implies an increased number of medical hospital beds, reduction in hospital demand, and optimization of hospital bed capacity. However, increasing the number of hospital beds relieves only temporarily overcrowding of medical wards and does not resolve the problem, because beds quickly fill and the problem returns. The major focus of lowering hospital demand is managing patients through community facilities and/or provide more services to the community that traditionally occur in hospital. A further approach is to accelerate discharges. In our Medicine ward there is a unit, known as Short Stay Area, which collects all the admissions from the ED and works as second level triage. After a 3-day observation period patients are discharged or assigned to the ward according to their different need of care.$^{15} \mathrm{~A}$ similar area organised at de- partmental level and shared between different specialists would be probably useful to allocate patients in the beds of a Medicine Department designed for intensity of cares rather than specialties. Transferring patients to appropriate facilities in short times could also increase bed hospital availability, and the presence of a case-manager in the medical department is essential to improve discharges of difficult patients.

In conclusion, an overburden hospital should be regarded as unsafe. Communities and policy makers should be aware of this and support health care designs, as well as health care spending, to face the growing demand for clinically and socially frail patients. Also, in designing future hospital scenarios it would be necessary to think about a correct ratio between beds in Internal Medicine and population, considering aging and clinical studies displaying an over-utilization of Internal Medicine beds compared with the use of beds in medical specialties and surgery, currently used to admit internal medicine patients.

\section{References}

1. Sprivulis PC, Da Silva JA, Jacobs IG, et al. The association between hospital overcrowding and mortality among patients admitted via Western Australian emergency departments. Med J Aust 2006;184:208-12.

2. Cameron PA. Hospital overcrowding: a threat to patient safety? Med J Aust 2006;184:203-4.

3. Nardi R, Gardellini A, Iori I. Internal Medicine wards overcrowding and clinical risk management: structural or systemic interventions needed? Ital J Med 2009;3:3-8.

Table 3. Critical issues and consequences of the hospitalization as outlier patient.

\begin{tabular}{|c|c|c|}
\hline Factors depending on & Critical issues & Possible consequences \\
\hline Physician & $\begin{array}{l}\text { - Outlying patients are visited after the other } \\
\text { patients allocated in the home ward } \\
\text { - Outlying patients are seen by different physicians } \\
\text { during hospital stay }\end{array}$ & $\begin{array}{l}\text { - Increasing hospital length of stay } \\
\text { - Lacking of a reference physician and limited } \\
\text { confidence in health facilities }\end{array}$ \\
\hline Nurse & $\begin{array}{l}\text { - Blood tests, therapies, and procedures of the } \\
\text { internal medicine wards are not familiar in other } \\
\text { wards (particularly in surgery wards) } \\
\text { - Surgery wards are less trained to manage medical } \\
\text { patient in critical conditions and less familiar with } \\
\text { health instruments (monitor, continuous positive } \\
\text { airway pressure device, continue infusion pumps) } \\
\text { - Knowledge of common internal medicine diseases } \\
\text { is limited and information at discharge of patient is } \\
\text { incomplete }\end{array}$ & $\begin{array}{l}\text { - Delaying in the diagnosis, increasing in } \\
\text { hospital length of stay, increasing risk of morbidity } \\
\text { - Increasing risk of morbidity and mortality } \\
\text { - Patient and caregiver dissatisfaction, increased } \\
\text { risk of early hospital readmission after discharge }\end{array}$ \\
\hline Work organization & $\begin{array}{l}\text { - Distance of the outlying patient from the physicians } \\
\text { assigned } \\
\text { - Discomfort in daily practice: } \\
\text { i) Finding patients, medical and therapy records } \\
\text { ii) Beginning and changing treatments } \\
\text { iii) Obtaining information } \\
\text { iv) Obtaining appropriate assistance when required } \\
\text { - Frail patient's discharge is poorly considered }\end{array}$ & $\begin{array}{l}\text { - Delay in emergency/urgency intervention, } \\
\text { increasing morbidity/mortality } \\
\text { - Lacking of cooperation between physician and } \\
\text { nurse, increasing clinical risk error, increasing } \\
\text { length of stay } \\
\text { - Increased risk of early hospital readmission } \\
\text { after discharge }\end{array}$ \\
\hline
\end{tabular}


4. Rockwood K, Song X, MacKnight C, et al. A global clinical measure of fitness and frailty in elderly people. CMAJ 2005; 173:489-95.

5. Nardi R, Scanelli G, Tragnone A, et al. Difficult hospital discharges in internal medicine wards. Intern Emerg Med 2007;2:95-9.

6. Wong HJ, Morra D, Caesar M, et al. Understanding hospital and emergency department congestion: an examination of inpatient admission trends and bed resources. Can J Emerg Med 2010;12:18-26.

7. Weissman JS, Rothschild JM, Bendavid E, et al. Hospital workload and adverse events. Med Care 2007;45:448-55.

8. Bagust A, Place M, Posnett JW, et al. Dynamics of bed use in accommodating emergency admission: stochastic simulation model. Br Med J 1999;319:155-8.

9. Harris A, Sharma A. Access block and overcrowding in emergency departments: an empirical analysis. Emerg Med J 2010;27:508-11.
10. Forero R, McCarthy S, Hillman K. Access block and emergency department overcrowding. Crit Care 2011; 15:216-22.

11. Bain CA, Taylor PG, Mcdonell G, Georgiou A. Myths of ideal hospital occupancy. Med J Aust 2010;192:42-3.

12. Green LV. How many hospital beds? Inquiry 20022003;39:400-12.

13. Richardson DB. Increase in patient mortality at 10 days associated with emergency department overcrowding. Med J Aust 2006;184:213-6.

14. Nardi R, Berti F, Greco A, et al. Complexity in hospital internal medicine departments: what are we talking about? Ital J Med 2013;7:142-55.

15. Serafini F, Bonanni L, Zancanaro A, et al. Area di accoglimento e degenza breve (ADB): parte integrante di un reparto di Medicina Interna organizzato per intensità di cure. Ital J Med 2012;6:242-7. 